\title{
PARCERIA ESCOLA - CLÍNICA NO ATENDIMENTO A CRIANÇAS PORTADORAS DE TRANSTORNOS GRAVES DO DESENVOLVIMENTO
}

Mônica Fujimura Leite

Núcleo de Apoio ao Desenvolvimento da Criança, no Programa Mãe Parananense, Consórcio Intermunicipal do Médio Paranapanema - CISMEPAR. E-mail: mokileite@gmail.com

\section{RESUMO}

Este artigo versa sobre o papel da escola enquanto parceria de tratamento com o atendimento clínico em crianças portadoras de transtornos graves do desenvolvimento. A inserção escolar tem efeitos terapêuticos nessas crianças, uma vez que a escola oferta papéis sociais, normas e referenciais identificatórios importantes para a retomada da constituição psíquica. Objetivou-se verificar esta associação, a partir da metodologia qualitativa, levantamento bibliográfico e o estudo de caso. Após dois anos de trabalho, verificou-se que houve uma mudança qualitativa de posição da criança analisada, em dois contextos escolares diferentes, a primeira sem possibilidade de trabalho para ela e a segunda acolhendo suas necessidades e abrindo-se à parceria com a clínica que a atende. As intervenções realizadas pela escola situam-se a partir de um posicionamento enquanto Outro e outro para a criança e isso teve como efeito um avanço em seu processo de constituição psíquica.

Palavras-chave: Psicanálise, criança, escola, transtorno grave do desenvolvimento

\section{SCHOOL PARTNERSHIP - CLINIC ON CALL CHILD CARRIER DISORDERS MAJOR DEVELOPMENT}

\begin{abstract}
This article deals with the role of the school as a partnership of treatment with the clinical care of children with serious developmental disorders. School inclusion has therapeutic effects in these children since the school offer social roles, rules and important identificatory reference for the resumption of psychic constitution. This study aimed to verify this association, from the qualitative methodology, literature review and the case study. After two years of treatment, it was found that there was a qualitative change child's position analyzed in two different school contexts, the first without the possibility of working for her and the second embracing their needs and opening up the partnership with the clinic treatment. Interventions by the school are located from a position as Other and other for the child and It had the effect of an improvement in their psyches constitution process.
\end{abstract}

KeyWords: Psychoanalysis, child, school, serious developmental disorder 
Uma das maiores dificuldades que estas famílias de crianças portadoras de transtornos graves do desenvolvimento encontram para seus filhos é a circulação social, sendo a inserção escolar no ensino regular o ponto - chave desta problemática (KUPFER, 2000). A partir da Idade moderna a escolarização no Brasil é obrigatória e desde então a escola passou a ser o lugar da infância (ARIÈS, 1978). Nas crianças portadoras de transtornos graves do desenvolvimento essa questão se torna capital. O tratamento desses casos, a partir da Psicanálise, consiste em retomar a estruturação psíquica interrompida pela eclosão do transtorno, e tal estruturação se dá pela intromissão das leis sociais na vida da criança (KUPFER; PETRI, 2000).

A escola, por sua vez, tem uma função de enlace com o social, pois trata-se de um espaço de transmissão da cultura, oferece, sustenta e modela lugares sociais para as crianças, seus pares e seus Outros ${ }^{1}$. Ao longo de alguns anos de inclusão escolar, associada a um tratamento adequado, verifica-se que a crianças apresentam uma estabilização, melhora e uma alteração em sua posição diante do Outro (KUPFER; PETRI, 2000).

No trabalho clínico com a criança, o analista intervém também neste aspecto, fazendo uma função de escuta e sustentação do lugar dessa criança no social (família e escola) e realizando o "tratamento do Outro" da criança (ZENONI, 1991 apud KUPFER; FARIA; KEIKO, 2007). Isso porque nesses casos a criança fica submetida ao imperativo de um Outro invasivo, não simbolizado. A relação da criança com o Outro encarnado não contou com a metáfora paterna, que possibilitaria a separação entre ela e o Outro, e ela poder se perguntar quem é ela para o Outro e criar respostas singulares a isso, contando com as ferramentas compartilhadas socialmente. Assim, o tratamento inclui esse movimento de separação entre a criança e seu Outro, sendo necessário então incluir nesse tratamento os elementos que fazem essa função para a criança, de modo a possibilitar a ela vivenciar um Outro barrado.

Com a criança, o trabalho é de auxiliá-la a realizar a separação, estabelecendo respostas mais elaboradas ao seu Outro, a partir dos jogos constituintes do sujeito, que possibilitam a construção do corpo e do eu no bebê (JERUSALINSKY, 2006) do transitivismo, que consiste no empréstimo da representação por parte do adulto às sensações sentidas no corpo do bebê, possibilitando-Ihe identificar-se com o discurso do adulto e descobrir-se como um corpo sensível e simbolizável (BERGÉS; BALBO, 2002). O fenômeno apontado nesta situação mostra uma indeterminação entre o sujeito agente da ação e o outro paciente da ação. A constituição do eu é concomitante à diferenciação do outro para o bebê. Segundo Lacan, isso acontece primeiro numa alienação ao outro, no estágio do espelho, mais especificamente no transitivismo, onde o bebê sente ciúme de outro bebê em uma cena em que considera que ele e o Outro se complementam. A origem da agressividade comparece, neste momento, onde, a partir dessa imagem vista, o bebê ao mesmo tempo antecipa a apreensão da forma global de seu corpo (formação do eu), e por outro lado, instala a experiência da intrusão, onde se confunde com o outro. Assim, antes de afirmar sua identidade, o eu se confunde com esta imagem que o forma e que o aliena antes de tudo. É por meio da imagem do outro que se produz na criança a apropriação de uma identidade e de seu corpo que ela não obteve ainda (LACAN, 1938/2003; LACAN, 1953-54/2009).

\section{METODOLOGIA}

O caso escolhido foi o de uma criança de 5 anos de idade, com quadro de transtorno grave do desenvolvimento. Quando chega para tratamento clínico psicanalítico, encontra-se em uma escola particular tradicional, de grande porte, com regras bem estabelecidas e sem muita relativização. A partir de uma intervenção do clínico, a criança muda para uma escola menor, que foi capaz de acolher as necessidades da criança e da família. O artigo analisa, após dois anos de

\footnotetext{
${ }^{1}$ De acordo com Lacan (1954-55/1992) o Outro (A) é aquele que fala. Não se identifica com o eu (a), em torno do qual centra-se a relação imaginária ao outro, no qual o sujeito se reconhece. Lacan diferencia o pequeno outro, que é o eu, imaginário, e o grande Outro, que está na função da fala. Posteriormente (1967/2003) diz que o Outro é o lugar da operação da linguagem.
} 
parceria, a evolução da criança, dentro do contexto escolar. Os dados foram recolhidos dos atendimentos com a psicóloga e de reuniões com a escola.

Esta pesquisa localiza-se dentro da metodologia qualitativa, onde a situação - problema é decorrente da experiência do pesquisador. A produção do conhecimento surge da relação entre sujeitos e objetos concretos, e a elaboração de uma resposta é uma interpretação da realidade, a partir da subjetividade do pesquisador, aliada às respostas anteriormente construídas no mundo científico (teoria). Uma análise qualitativa investiga os significados e as estruturas, e o comportamento humano investigado se dá na interação social e dentro do contexto do sujeito (MINAYO \& SANCHES, 1993; MADUREIRA, 2000; GAMBOA, 2009). O método utilizado foi o de Estudo de Caso, o qual é proveniente da tradição médica e propõe adquirir um conhecimento do fenômeno estudado a partir da exploração intensa de um único caso, com o objetivo de apreender a totalidade de uma situação. Ela visa estudar um sujeito e seu ponto de vista, sendo caracterizado por uma interação delimitada no tempo e espaço, realizada dentro de um contexto específico cultural no qual o evento se desdobra, e posterior extensão e validação dos resultados do estudo, a partir de um retorno à teoria. (GOLDEMBERG, 2003).

\section{RESULTADOS}

Quando Joãozinho (nome fictício) chegou para atendimento psicanalítico na clínica, sua permanência na escola encontrava-se ameaçada. Ele gritava, chorava, agredia os outros e si mesma, e acabava indo algumas vezes com, outras sem o uniforme. Durante o percurso, jogava-se no chão e ia na maioria das vezes carregada. Muitas vezes, ao chegar ao portão, não conseguia ser deixada, retornando para casa. Quando conseguia ficar, entrava chorando muito, fugia da sala de aula e quando permanecia, não participava das atividades, andava pela sala, mexia nos brinquedos. Quando era interditado, agredia-se e aos colegas e professores, precisando ser contido ou retirado da escola. A inclusão de fato não ocorria, uma vez que ele estava inserida no mesmo ambiente, mas não participava de forma efetiva da rotina e cultura escolares.

Urgia então pensar em uma nova possibilidade para esta criança, uma vez que tanto para ela quanto para a instituição esta relação estava se tornando impossível. Joãozinho foi então direcionado, após um contato prévio, a uma nova escola, com um espaço físico menor, e um olhar para a individualidade e as necessidades dele. A equipe pedagógica daquela instituição relativizava o ideal pedagógico, abrindo espaço para acolhê-lo.

Os profissionais da escola falavam com Joãozinho considerando que entendia, pediam-lhe que participasse das atividades, da mesma forma que às demais crianças, porém aceitavam até onde ele conseguia responder a esses pedidos. Se ele precisava sair da sala, a auxiliar o acompanhava, e depois de um tempo o reconduzia de volta ao seu lugar. Suas ações, por mais que destoassem do esperado, eram reconhecidas enquanto uma produção e acolhidas dentro da atividade proposta, dentro da turma, e posteriormente também remetidas à família.

A escola também propiciou encontros e experiências, como o contato físico entre as crianças e brincadeiras que exploravam a experimentação de diversos materiais e texturas, e jogos estruturantes de expectativa e antecipação, superfície e esburacamento, que possibilitaram a ele experiências de satisfação, ajudando-o no engate da palavra ao corpo. Os profissionais da escola, cotidianamente, anteciparam e contextualizaram as ações de Joãozinho, impedindo-o que se machucasse e aos coleguinhas, auxiliando-o a expressar-se de formas socialmente aceitas. Os profissionais não encaravam suas estereotipias ou ações agressivas como parte de uma nosografia, mas buscando uma forma de expressão de Joãozinho de que algo não ia bem com ele, e além disso, buscavam uma forma de inseri-las dentro do plano pedagógico.

Por outro lado, a escola também fazia referência às normas culturais no cotidiano escolar, na rotina, nos hábitos de higiene, nos lugares e espaços escolares, nas festividades da cultura, bem como nos horários e atividades programadas. 
Atualmente, após dois anos de trabalho de parceria do trabalho clínico com a escola, Joãozinho ainda encontra-se bem destoante do restante de sua turma: apresenta pouco tempo de concentração, alguns episódios de agressão e ainda tem dificuldades de se comunicar pela palavra. Mas já realiza as atividades, interage e convoca os amigos e funcionários da escola, os episódios diminuíram de frequência, reconhece-se como de sua turma, submetendo-se à rotina escolar e realizando todas as atividades coletivas.

\section{DISCUSSÃO}

A entrada na escola implica, para a criança, na apresentação e adequação às normas sociais. Ela instaura o significado coletivo, construído socialmente, que tem que ser aceito por ela. O apontamento para a norma é um dos pontos - chave da instituição escolar. De acordo com Lajonquière (2002), um adulto educa uma criança a partir da diferença estabelecida entre eles, ordenando o mundo, a partir da arbitrariedade simbólica do permitido e do proibido. A criança se sujeita a essa arbitrariedade em nome da promessa de que no futuro poderá ocupar o lugar do adulto. Esta dinâmica instaura o desejo, uma vez que a criança aprende que não é possível ter tudo e, portanto, só lhe resta desejar. Petri (2003) ainda nos lembra que as instituições funcionam regidas por um ordenamento ditado por parâmetros que fazem referência à lei paterna. Esta tem uma função moderadora e pacificadora em relação ao individual e ao coletivo, regulando as relações, promovendo o laço social e as identificações.

Porém, no caso de Joãozinho, tal exigência proveniente da primeira escola não estava sendo estruturante. Ele não possuía estofo simbólico suficiente para suportar o que essas regras impunham. Vivendo ainda no automatismo das estereotipias, no desregramento pulsional de seu corpo, cujo controle ainda era de seu Outro encarnado; apresentou-se por demais terrorífica e incompreensível a inserção em um mundo ordenado por leis que não lhe faziam sentido, inscrevendo revolta e caos, ao invés de referência.

Ele então respondia exercendo sua ilusão de onipotência e agredindo isso que nem diferenciava como vindo de dentro ou de fora, de si ou do outro. Joãozinho ainda estava vivenciando uma mistura com o outro, sem poder localizar suas sensações, impulsos e desejos, e nem lidar com as demandas que vinham dos adultos.

Na segunda escola, a individualidade de Joãozinho foi considerada sem perder de vista o contexto e a função da escola: o apontamento para a norma. Assim, este foi o carro-chefe do trabalho realizado, em parceria com clínica: a inscrição da lei para Joãozinho, retirando-o da condição de exceção e possibilitando-Ihe a existência no mundo humano, a partir do barramento dos atos agressivos, do uso da palavra e cumprimento das regras escolares. A equipe pedagógica apresentou a lei paterna a esta criança. Ainda mais, ao mostrar a ela sua própria submissão a esta lei, ofereceu-Ihe modelo de como lidar com as impossibilidades que acometem a todos enquanto seres humanos.

De acordo com Lajonquière (2002) exigir que a criança encarne os ideais projetados sobre ela não deixa o intervalo necessário que lhe possibilite o deslocamento da demanda educativa. Ele nos lembra que a educação só é possível a partir de uma denegação da demanda. Ou seja, é necessário que um adulto demande, mas deixe implícito que depende da criança atendê-lo. Desta forma ele abre para a criança a possibilidade de inscrever uma diferença e recuperar para si o desejo inscrito no ato educativo. A equipe da segunda escola colocou Joãozinho enquanto destinatário de sua mensagem, a partir da aposta e oferta de significantes, dirigindo-Ihe também demandas, na suposição de que ela é um sujeito capaz de realizá-las. Por outro lado, permitiu-lhe relativizar tal demanda, ao aceitar as respostas que ele era capaz de dar naquele momento.

Esta equipe também foi capaz de realizar uma função de extrema importância no caso de crianças portadoras de transtornos graves, nas quais um sujeito ainda não está constituído: a de atribuir uma autoria às produções da criança, lendo-as enquanto uma demanda dirigida a ele, a 
partir da suposição de um sujeito nela. O que Jerusalinsky (2006) fala sobre uma mãe diante de seu bebê pode ser aplicado estruturalmente na relação da equipe pedagógica (posicionados enquanto Outros encarnados) com Joãozinho. $O$ adulto, segundo a autora, engaja a criança num circuito de Demanda e Desejo, oferecendo uma sustentação que permite fazer surgir novas respostas do automatismo biológico no qual ela se encontrava.

A psicanalista ainda afirma que o desenvolvimento da criança é proveniente de um destempo; o surgimento de novas aquisições necessita ser antecipado pelo Outro, a partir dos ideais da cultura. No caso de Joãozinho, antes da entrada na escola, essa antecipação não ocorrera, o circuito pulsional dele não foi atrelado ao campo da demanda e desejo de seu Outro encarnado, falhando a operação de alienação, a partir do qual ele poderia sustentar sua identificação primordial. A equipe escolar pôde assumir então, essa função para esta criança: ao remetê-la a um ideal, projetando-lhe uma imagem a partir de seu desejo, ela pôde se ver e se identificar. Pode-se dizer que os adultos da equipe sustentaram um lugar de Outro para Joãozinho.

Além disso, os adultos e crianças da escola assumiram o lugar de outro para ele, ao oferecer modelos de reconhecimento das sensações e sentimentos no próprio corpo e da demonstração dos mesmos através de ações e palavras. A partir do transitivismo (BERGÉS \& BALBO, 2002) realizado, ajudaram Joãozinho a realizar a erogeneização de seu próprio corpo, de modo a reconhecer as sensações da dor e do prazer e atrelá-las à palavra, o que permitiu-lhe representar-se no discurso. Isso permitiu a esta criança transformar estereotipias em atos intencionais, movimentos descontextualizados em um brincar e ecolalias e gritos em um discurso direcionado dentro da escola.

Ao longo desse tempo, pôde-se perceber uma mudança de posição em Joãozinho dentro da escola, onde podemos pensar, a partir de Jerusalinsky (2006) que, à medida em que a criança realiza aquisições, arma-se uma extensão do circuito pulsional e da cadeia significante, de modo que ela passa a contar com instrumentos de resposta ao Outro de maneira menos sintomática e mais articulada com um desejo próprio.

\section{CONCLUSÃO}

Podemos dizer que atualmente, há um sujeito em vias de constituição em Joãozinho, e que o trabalho da escola foi fundamental, em parceria com o da clínica. Hoje ele circula socialmente, coloca seu discurso para ser escutado, brinca, sofre perdas e broncas, aprende, e é reconhecido enquanto uma criança, não apenas portadora de um transtorno grave do desenvolvimento. Assim, esta escola incluiu no campo da educação a dimensão de um sujeito desejante, deixando espaço para ele comparecer, ao não definir por completo o processo de ensino e reconhecendo cada passo dado por ele, e não somente o esperado. Realizou o lançamento da criança na dimensão do ideal, ao demandar-lhe responder do lugar de aprendiz e de criança esperado para sua idade, deixando porém o intervalo necessário que lhe possibilitou o deslocamento da demanda educativa. Além disso, ofertou-Ihe modelos de identificação e experiências que lhe permitiram avançar em seu percurso de apropriação de seu corpo, construção de sua identidade e sua relação ao outro.

O caso de Joãozinho demonstrou que o contexto de tratamento de crianças portadoras de transtornos graves do desenvolvimento, inclui, além da escuta da criança, um tratamento do Outro da criança, seu entorno social: família, escola e os demais elementos que ocupam essa função para ela. O momento lógico no qual elas se encontram, onde os elementos constituintes de sua subjetividade ainda estão se inscrevendo necessitam da antecipação, sustentação e confirmação daqueles que assumem para ela esse lugar de Outro. A escola e o clínico podem assumir essa função, junto com a família da criança. 


\section{REFERÊNCIAS}

ARIÈS, P. História social da criança e da família. Rio de Janeiro: Zahar, 1978.

BERGÈS, J.; BALBO, G. Jogo de Posições da Mãe e da Criança, Ensaio Sobre o Transitivismo. Porto Alegre: CMC Editora, 2002.

GAMBOA, S., S. Pesquisa Qualitativa. Palestra proferida na Universidade Estadual de Londrina no Tópico Especial em Educação: Projeto de Pesquisa Científica: fundamentos lógicos. Londrina, (mai.2009).

GOLDEMBERG, M. A Arte de Pesquisar: como fazer pesquisa qualitativa em ciências sociais. 7 ed. Rio de Janeiro: Record, 2003.

JERUSALINSKY, J. Enquanto o futuro não vem: a psicanálise na clínica interdisciplinar com bebês. 2 ed. Salvador: Àgalma, 2006.

KUPFER, M.C.M. Educação para o futuro. São Paulo: Escuta, 2000.

KUPFER, M. C. M.; FARIA, C.; KEIKO, C. O tratamento institucional do Outro na psicose infantil e no autismo. Arq. bras. psicol. Rio de Janeiro, v.59, n.2, p. 1-9, dez. 2007.

KUPFER, M. C.; PETRI, R. Por que ensinar a quem não aprende? Estilos da Clínica: Revista sobre a Infância com Problemas, v.5, n.9, p. 109-117, 2000.

LACAN, J. Os complexos familiares na formação do indivíduo: ensaio de análise de uma função em psicologia (1938). In: LACAN, Jacques. Novos Escritos. Rio de Janeiro: Jorge Zahar Editor, 2003. p.29- 90 .

LACAN, J. O Seminário, livro 1: os escritos técnicos de Freud (1953-54). 2. ed. Rio de Janeiro: Zahar, 2009.

LACAN, J. O eu na teoria de Freud e na técnica da psicanálise. (1954-55). 3 ed. Jorge Zahar: Rio de Janeiro, 1992.

LAJONQUIÈRE, L. Infância e ilusão (psico)pedagógica: escritos de psicanálise e educação. 3 ed. Petrópolis: Vozes, 2002.

MADUREIRA, A.F.A. Metodologia Qualitativa. Epistemologia positivista e instrumentalismo metodológico: a metodologia como o "caminho para a verdade". Texto produzido para fins didáticos do curso de Metodologia Científica no curso de Ciências Jurídicas. Instituto de Educação Superior de Brasília, Brasília, 2000.

MINAYO, M.C.S. \& SANCHES, O. Quantitativo - Qualitativo: oposição ou complementariedade? Cad. Saúde Públ. Rio de Janeiro, v. 9, p. 239 - 262, jul/set, 1993.

PETRI, R. Psicanálise e educação o tratamento da psicose infantil: quatro experiências institucionais. São Paulo: Annablume; FAPESP,2003. 